\title{
GMR
}

\section{Mutations in codons 12 and 13 of $K$-ras exon 2 in colorectal tumors of Saudi Arabian patients: frequency, clincopathological associations, and clinical outcomes}

\author{
J. Zekri',2, A. Al-Shehri ${ }^{3}$, M. Mahrous ${ }^{4}$, S. Al-Rehaily ${ }^{3}$, T. Darwish ${ }^{5}$, \\ S. Bassi ${ }^{1}$, H. El Taani ${ }^{6}$, A. Al Zahrani ${ }^{6}$, S. Elsamany ${ }^{6,7}$, J. Al-Maghrabi ${ }^{1,8}$ \\ and B.B. Sadiq ${ }^{1}$ \\ ${ }^{1}$ King Faisal Specialist Hospital Research Centre, Oncology, Jeddah, \\ Saudi Arabia \\ ${ }^{2}$ College of Medicine, Al-Faisal University, Saudi Arabia \\ ${ }^{3}$ National Guard Hospital, Oncology, Jeddah, Saudi Arabia \\ ${ }^{4}$ King Fahad Hospital, Oncology, Madinah, Saudi Arabia \\ ${ }^{5}$ King Abdullah Medical City and Oncology Center, Oncology, Jeddah, \\ Saudi Arabia \\ ${ }^{6}$ King Abdullah Medical City, Oncology, Mekkah, Saudi Arabia \\ ${ }^{7}$ Oncology Centre, Mansoura University, Mansoura, Egypt \\ ${ }^{8}$ Department of Pathology, King Abdulaziz University, Jeddah, Saudi Arabia \\ Corresponding author: J. Zekri \\ E-mail:.jmzekri@hotmail.com \\ Genet. Mol. Res. 16 (1): gmr16019369 \\ Received September 22, 2016 \\ Accepted December 23, 2016 \\ Published February 16, 2017 \\ DOI http://dx.doi.org/10.4238/gmr16019369
}

Copyright (C) 2017 The Authors. This is an open-access article distributed under the terms of the Creative Commons Attribution ShareAlike (CC BY-SA) 4.0 License.

\begin{abstract}
Mutations in codons 12/13 of $K$-ras exon 2 are associated with reduced benefit from anti-epidermal growth factor receptor antibody treatment for metastatic colorectal cancer (CRC). Here, we evaluated the frequency of $K$-ras mutations and their relationship with clinicopathological features and treatment outcomes in Saudi
\end{abstract}

Genetics and Molecular Research 16 (1): gmr16019369 
Arabian patients with CRC. The genetic status of $K$-ras was determined in 300 patients diagnosed with CRC. Clinical information was collected retrospectively. $K$-ras was wild-type in $58 \%$ and mutated in $42 \%$ of the tumors. Most mutations were at codon $12(89 \%)$ and were associated with metastasis [odds ratio $(\mathrm{OR})=1.38(95 \% \mathrm{CI}=1.14-1.67]$ and occurrence of $>40 \mu \mathrm{g} / \mathrm{L}$ carcinoembryonic antigen $(\mathrm{CEA})$ [OR $=1.33$ (1.1-1.74)] during diagnosis. Patients in stages I-III of the disease with wild-type $K$-ras tumors had a median relapse free survival (RFS) of 29 months in contrast to 22 months for those with the mutated $K$-ras tumor $(\mathrm{P}=0.0357)$. In multivariate analysis, only the stage of the disease significantly predicted RFS ( $\mathrm{P}=$ 0.001). Patients in stage IV of CRC with the wild-type $K$-ras tumor did not reach the median overall survival (OS), whereas patients with the mutated $K$-ras tumor survived for 23.5 months $(\mathrm{P}=0.044)$. CEA level $>40 \mu \mathrm{g} / \mathrm{L}(\mathrm{P}$ $=0.004)$ and status of $K$-ras $(\mathrm{P}=0.044)$ were independent predictors of OS. This is the largest study investigating $K$-ras mutations in patients with $\mathrm{CRC}$ in the Middle East. Mutations were associated with advanced stage of CRC, higher serum CEA, shorter RFS and OS.

Key words: Colorectal cancer; Saudi Arabia; K-ras; exon 2; Codon 12/13; Relapse-free survival

\section{INTRODUCTION}

Colorectal cancer (CRC) is the third-most common cancer in men and the fourthmost common cancer in women world-wide (Parkin et al., 2005). The treatment outcome of patients with metastatic CRC has improved in the past decade, mainly due to the introduction of new and active cytotoxic chemotherapeutic agents and targeted drugs (Chau and Cunningham, 2009; Kopetz et al., 2009). The latter include monoclonal antibodies with high selectivity and affinity for the epidermal growth factor (EGFR) receptor, which is overexpressed in $25-80 \%$ of the colorectal cancer tumors (Salomon et al., 1995; Porebska et al., 2000). These antibodies, such as cetuximab and panitumumab, can evade chemotherapy resistance (Cunningham et al., 2004) and improve response rate (RR) and progression free survival (PFS) when combined with FOLFIRI and FOLFOX chemotherapy as the first line of treatment (Van Cutsem et al., 2009; Douillard et al., 2010).

Mutations in the Ras oncogene are reported in $58 \%$ of colonic adenomas that are larger than $1 \mathrm{~cm}$ and in $47 \%$ of all CRC tumors (Vogelstein et al., 1988). The product of $K$-ras regulates two signaling pathways, PI3K/AKT and RAF/MEK/ERK, which control cell proliferation, differentiation, and programed cell death. The most common mutations of $K$-ras occur in codons 12 and 13 of exon 2. The antitumor activity of the anti-EGFR antibody is lessened in patients with CRC who have the mutated form of $K$-ras, compared to those who have the wild-type gene. Therefore, anti-EGFR-based therapy is only indicated in patients with tumors expressing wild-type $\mathrm{K}$-ras and $\mathrm{N}$-ras.

A combined analysis of four randomized studies, which included 2,292 patients with metastatic CRC (mCRC) mostly from the West, showed that $40 \%$ had tumors expressing mutated $K$-ras (Ibrahim et al., 2010). However, there is dearth of data on the frequency of occurrence of $K$-ras mutations and their impact on the treatment outcomes in Asian and Middle Eastern

Genetics and Molecular Research 16 (1): gmr16019369 
patients. The aim of this study was to investigate the association of the genetic status of $K$-ras with clinicopathological features and clinical outcome in patients with CRC from Saudi Arabia.

\section{MATERIAL AND METHODS}

\section{Patients and mutation analysis of $K$-ras}

We studied 300 consecutive patients diagnosed with CRC between September 2001 and April 2012 in five hospitals in the western province of Saudi Arabia. The genetic status of $K$-ras was determined as requested by the managing oncologist during the patients' routine clinical evaluation. Mutation analysis of $K$-ras was performed by the Biomnis laboratory. Formalin-fixed, paraffin-embedded materials from colorectal carcinomas were used for DNA extraction. An array kit was used for detection of mutations (p.G12S, p.G12R, p.G12C, p.G12D, p.G12A, p.G12V, p.G13D, and p.G13R) within codons 12 and 13 of exon 2 of $K$-ras.

\section{Selection of clinicopathological features}

Clinicopathological features selected for association testing included the gender and age of the patients, the site of the primary tumor, carcinoembryonic antigen (CEA) level, cancer stage based on the criteria of the American Joint Committee on Cancer (AJCC) and tumor-node-metastasis (TNM) stage, amount of perforation and bleeding during initial diagnosis, tumor grade, extent of lymphovascular invasion (LVI) and perineural invasion (PNI), and distance from the anal verge (for rectal tumors). Tumors of the caecum, ascending colon, and the proximal transverse colon were labeled as right-sided tumors; those distal to the proximal part of transverse colon (mid-transverse, distal transverse, descending, sigmoid, and the rectum) were labeled as left-sided tumors.

\section{Data analysis}

All data was retrospectively collected from paper and electronic records. Associations between clinicopathological features and $K$-ras status was analyzed using the chi-square test, the independent $t$-test and the Mann-Whitney test. Cox regression was used for multivariate analysis. Survival tables and Kaplan Meier analysis were used to determine the relapse free survival (RFS) and overall survival (OS). Log rank testing was used to explore the differences in RFS and OS between groups. The SPSS software (version 12) was used for all analyses.

\section{Ethical consideration}

Institutional review boards (ethics committees) at all participating sites approved the study protocol prior to the study.

\section{RESULTS}

\section{Patients}

Patient characteristics are shown in Table 1 . The majority were male (61\%), with left- 
sided tumors. About half of the patients had stage IV tumors and most tumors were of grade II. Mutated K-ras was found in $41.7 \%$ cases in the whole cohort, with $89 \%$ of the mutations arising in codon 12 (Table 2).

\section{Table 1. Characteristics of patients at the time of diagnosis.}

\begin{tabular}{l|c}
\hline Characteristic & Number $(\%)^{\mathrm{a}}$ \\
\hline Male/females & $182(61) / 118(39)$ \\
\hline Median age [range] (year) & $54.5(20-86)$ \\
\hline Tumor site & $63 / 296(21)$ \\
\hline Right & $233 / 296(79)$ \\
\hline Left & $4 / 300(1)$ \\
\hline Missing data & $3(1)$ \\
\hline Stage at diagnosis & $71(24)$ \\
\hline I & $63(21)$ \\
\hline II & $163(54)$ \\
\hline III & $12(4)$ \\
\hline IV & $248(83)$ \\
\hline Grade & $40(13)$ \\
\hline I & \\
\hline III & $91 / 245(37)$ \\
\hline LVI & $154 / 245(63)$ \\
\hline Present & $55 / 300(18)$ \\
\hline Absent & \\
\hline Missing data & $35 / 230(15)$ \\
\hline PNI & $195 / 230(85)$ \\
\hline Present & $70 / 300(23)$ \\
\hline Absent & \\
\hline Missing data & \\
\hline
\end{tabular}

${ }^{a}$ Except where indicated. LVI = Lymphovascular invasion; PNI = Perineural invasion.

\section{Table 2. Genetic status of $K$-ras.}

\begin{tabular}{|c|c|c|c|}
\hline Stage & $\mathrm{N}$ & Mutant [number (\%)] & Codon [number (\%)] \\
\hline \multirow[t]{3}{*}{ All stages } & \multirow[t]{3}{*}{300} & \multirow[t]{3}{*}{$125(41.7)$} & Codon $12=104 / 117(89)$ \\
\hline & & & Codon $13=13 / 117(11)$ \\
\hline & & & Missing 8/125 (6) \\
\hline \multirow[t]{2}{*}{ Stage I/II /III at initial diagnosis } & \multirow[t]{2}{*}{137} & \multirow[t]{2}{*}{$43(31.4)$} & Codon $12=36 / 43(84)$ \\
\hline & & & Codon $13=7 / 43(16)$ \\
\hline \multirow[t]{3}{*}{ Stage IV at initial diagnosis } & \multirow[t]{3}{*}{163} & \multirow[t]{3}{*}{$82(50.3)$} & Codon $12=68 / 74(92)$ \\
\hline & & & Codon $13=6 / 74(8)$ \\
\hline & & & Missing 8/82 (10) \\
\hline \multirow[t]{2}{*}{ Stage I/II /III at last follow-up ${ }^{a}$} & \multirow[t]{2}{*}{77} & \multirow[t]{2}{*}{$22(28.6)$} & Codon $12=18 / 22(82)$ \\
\hline & & & Codon $13=4 / 22(18)$ \\
\hline \multirow[t]{3}{*}{ Stage IV at last follow-up } & \multirow[t]{3}{*}{223} & \multirow[t]{3}{*}{$103(46.2)$} & Codon $12=86 / 95(91)$ \\
\hline & & & Codon $13=9 / 95(10)$ \\
\hline & & & Missing 8/103 (8) \\
\hline
\end{tabular}

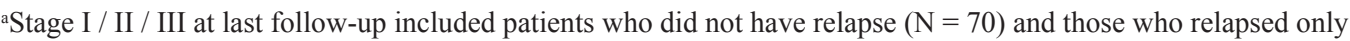
locally in the colon and were surgically salvaged with no evidence of disease at any other sites $(N=7)$.

\section{Relationship between the genetic status of $K$-ras and clinicopathological features}

Table 3 shows the frequency and association of clinicopathological features of interest in patients who harbored the mutant and wild-type $K$-ras tumors, respectively. For example, 15,19 , and $66 \%$ of the patients with mutant-type $K$-ras tumors presented with stage II, III, 
and IV of the disease, respectively. This indicates that patients with mutant $K$-ras tumors are more likely to present with the advanced stage of the disease. The percentage of patients with mutated $K$-ras tumors correlated positively with the stage $(\mathrm{P}=0.002)$ or metastasis $(\mathrm{P}=0.001)$ of the disease at the time of initial diagnosis. Gender, age, the site of the primary tumor, stage of the cancer (T stage or N stage), grade, LVI, PNI, and presence of obstruction and bleeding during the initial presentation did not differ significantly between patients with wild-type or mutated $K$-ras tumors. Mean serum CEA at initial presentation was higher in patients with the mutated than with the wild-type $K$-ras (279 vs $118 \mu \mathrm{g} / \mathrm{L}, \mathrm{P}=0.02)$.

Table 3. Associations between clinicopathological features and genetic status of $K$-ras.

\begin{tabular}{|c|c|c|c|}
\hline & $\mathrm{N}$ & Mutant / wild type (\% / \%) & Statistical evaluation \\
\hline Gender & & & \multirow{3}{*}{$\mathrm{OR}=1.1(95 \% \mathrm{CI}=0.84-1.4), \mathrm{P}=0.97$} \\
\hline Males & 182 & $58 / 62$ & \\
\hline Females & 118 & $42 / 38$ & \\
\hline Age & & & \multirow[t]{3}{*}{$\mathrm{OR}=1.1(95 \% \mathrm{CI}=0.84-1.4), \mathrm{P}=0.523$} \\
\hline$\leq 45$ years & 90 & $32 / 29$ & \\
\hline$>45$ years & 210 & $68 / 71$ & \\
\hline Location of tumor & & & \multirow[t]{3}{*}{$\mathrm{OR}=1.1(95 \% \mathrm{CI}=0.84-1.4), \mathrm{P}=0.73$} \\
\hline Right & 63 & $20 / 22$ & \\
\hline Left & 233 & $80 / 78$ & \\
\hline T Stage $^{\mathrm{a}}$ & & & \multirow[t]{4}{*}{$\mathrm{P}=0.489$} \\
\hline $\mathrm{T} 2$ & 21 & $8.2 / 9$ & \\
\hline T3 & 147 & $56 / 62$ & \\
\hline $\mathrm{T} 4$ & 78 & $36 / 29$ & \\
\hline N Stage & & & \multirow[t]{4}{*}{$\mathrm{P}=0.088$} \\
\hline N0 & 87 & $30 / 41$ & \\
\hline N1 & 95 & $40 / 41$ & \\
\hline N2 & 53 & $30 / 18$ & \\
\hline M Stage & & & \multirow[t]{3}{*}{$\mathrm{OR}=1.38(95 \% \mathrm{CI}=1.14-1.67), \mathrm{P}=0.001$} \\
\hline M0 & 137 & $34 / 54$ & \\
\hline M1 & 163 & $66 / 46$ & \\
\hline AJCC Stage $^{\mathrm{b}}$ & & & \multirow[t]{4}{*}{$\mathrm{P}=0.002$} \\
\hline II & 71 & $15 / 30$ & \\
\hline III & 63 & $19 / 23$ & \\
\hline IV & 163 & $66 / 47$ & \\
\hline $\mathrm{Grade}^{\mathrm{c}}$ & & & \multirow[t]{4}{*}{$\mathrm{P}=0.448$} \\
\hline $\mathrm{I}$ & 12 & $4 / 4$ & \\
\hline II & 248 & $86 / 81$ & \\
\hline III & 40 & $10 / 15$ & \\
\hline LVI & & & \multirow[t]{3}{*}{$\mathrm{OR}=0.89(95 \% \mathrm{CI}=0.74-1.1), \mathrm{P}=0.287$} \\
\hline Yes & 91 & $33 / 40$ & \\
\hline No & 154 & $67 / 60$ & \\
\hline PNI & & & \multirow[t]{3}{*}{$\mathrm{OR}=0.93(95 \% \mathrm{CI}=0.71-1.21), \mathrm{P}=0.599$} \\
\hline Yes & 35 & $14 / 16$ & \\
\hline No & 195 & $86 / 84$ & \\
\hline Obstruction & & & \multirow[t]{3}{*}{$\mathrm{OR}=1.05(95 \% \mathrm{CI}=0.8-1.8), \mathrm{P}=0.698$} \\
\hline Yes & 52 & $19 / 18$ & \\
\hline No & 231 & $81 / 82$ & \\
\hline Bleeding & & & \multirow[t]{3}{*}{$\mathrm{OR}=1.04(95 \% \mathrm{CI}=0.85-1.3), \mathrm{P}=0.70$} \\
\hline Yes & 130 & $48 / 45$ & \\
\hline No & 152 & $53 / 55$ & \\
\hline CEA at Presentation & & & \multirow[t]{3}{*}{$\mathrm{OR}=1.33(95 \% \mathrm{CI}=1.1-1.74), \mathrm{P}=0.32$} \\
\hline $0-40 \mu \mathrm{g} / \mathrm{L}$ & 134 & $56 / 71$ & \\
\hline$>40 \mu \mathrm{g} / \mathrm{L}$ & 74 & $44 / 29$ & \\
\hline
\end{tabular}

LVI = Lymphovascular invasion; PNI = Perineural invasion. ${ }^{\text {a }} \mathrm{T} 1$ tumors $(\mathrm{N}=2)$ and ${ }^{\mathrm{b}}$ Stage $\mathrm{I}$ tumors $(\mathrm{N}=3)$ were excluded due to small numbers of patients; ${ }^{\mathrm{C}} \mathrm{P}$ value is for all patients $(\mathrm{P}=0.205$ when grade I tumors were excluded). RR: relative risk.

Genetics and Molecular Research 16 (1): gmr16019369 
Serum CEA $>40 \mu \mathrm{g} / \mathrm{L}$ was more frequent in patients with the mutated $K$-ras tumors than in patients with the wild-type $K$-ras tumors, which is consistent with this observation (Table $3)$. The distance of the rectal tumors from the anal verge did not differ with the genetic status of $K$-ras $(8.7$ vs $8.1 \mathrm{~cm}, \mathrm{P}=0.633)$.

\section{Relationship between the genetic status of $K$-ras and treatment outcomes}

Sixty-seven patients in stages I-III of CRC at the time of the initial diagnosis had a relapse (49\%) after a median duration of 21 months of follow-up. The relapse rate was not statistically different in patients with the mutated vs the wild-type $K$-ras tumors (58vs $45 \%$, hazard ratio [HR] 1.3 [95\% CI $=0.93-1.8], \mathrm{P}=0.143$ ). However, the median RFS was 22 months for patients with the mutated and 29 months for patients with the wild-type $K$-ras tumors (Log rank $\mathrm{P}=0.0357$; Figure 1). The number of patients in the $\mathrm{N}$ stage $(\mathrm{P}=0.0003)$, AJCC stage $(\mathrm{P}=0.0027)$, and the genetic status of $K$-ras $(\mathrm{P}=0.0357)$ significantly influenced RFS in the univariate analysis, but only the $\mathrm{N}$ stage $(\mathrm{P}=0.001)$ remained statistically significant in the multivariate analysis (Table 4).

\begin{tabular}{|c|c|c|c|c|}
\hline \multirow[b]{2}{*}{ Factors } & \multicolumn{2}{|c|}{ RFS (137 patients with stages I-III at diagnosis) } & \multicolumn{2}{|c|}{ OS (163 patients with stage IV at diagnosis) } \\
\hline & Univariate analysis & Multivariate comparisons & Univariate analysis & Multivariate comparisons \\
\hline$\overline{\operatorname{Age}(\leq 45 \text { vs }>45 \text { years })}$ & $\mathrm{P}=0.484$ & - & $\mathrm{P}=0.246$ & - \\
\hline CEA $(>40 v s \leq 40 \mu \mathrm{g} / \mathrm{L})$ & $\mathrm{P}=0.547$ & - & $P=0.0019$ & $\begin{array}{c}\mathrm{P}=0.004 \\
\mathrm{RR}=3.1(95 \% \mathrm{CI}=1.4-6.8)\end{array}$ \\
\hline Site (right $v$ left) & $\mathrm{P}=0.847$ & - & $\mathrm{P}=0.975$ & - \\
\hline T stage & $\mathrm{P}=0.381$ & - & $\mathrm{P}=0.125$ & - \\
\hline $\mathrm{N}$ stage & $P=0.0003$ & $\begin{array}{c}\mathrm{N} 1 \text { vs } \mathrm{N} 0: \mathrm{P}=0.639 \\
\mathrm{RR}=1.15(95 \% \mathrm{Cl} 0.65-2.0) \\
\mathrm{N} 2 \text { vs } \mathrm{N0} \mathrm{P}<0.0001 \\
\mathrm{RR}=3.3(95 \% \mathrm{CI}=1.7-6.2)\end{array}$ & $\mathrm{P}=0.970$ & - \\
\hline AJCC stage (I-III) & $\mathrm{P}=0.0027$ & $\mathrm{P}=0.051$ & Not applicable & - \\
\hline Grade & $\mathrm{P}=0.6706$ & - & $\mathrm{P}=0.1218$ & - \\
\hline$\overline{\mathrm{LVI}}$ & $\mathrm{P}=0.1689$ & - & $\mathrm{P}=0.388$ & - \\
\hline$\overline{\mathrm{PNI}}$ & $\mathrm{P}=0.1904$ & - & $\mathrm{P}=0.468$ & - \\
\hline K-ras (mutated $v s$ wild-type) & $\mathrm{P}=0.0357$ & $\mathrm{P}=0.262$ & $\mathrm{P}=0.023$ & $\begin{array}{c}\mathrm{P}=0.044 \\
\mathrm{RR}=2.2(95 \% \mathrm{CI}=1.0-4.7)\end{array}$ \\
\hline
\end{tabular}

Factors significant on univariate analysis were entered into multivariate analysis. LVI = Lymphovascular invasion; PNI $=$ Perineural invasion. Bold indicates statistical significance $(\mathrm{P}<0.05)$.

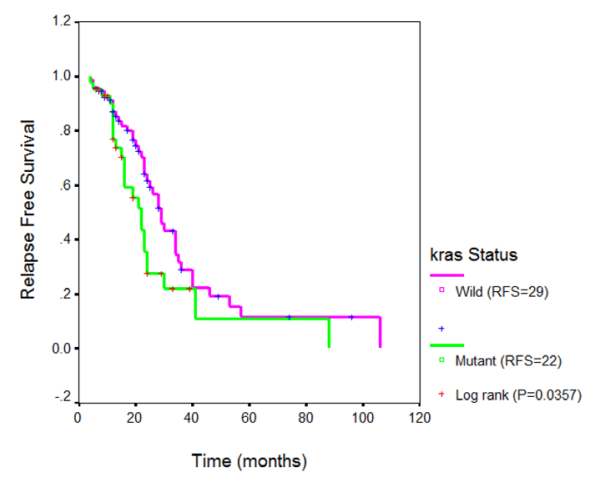

Figure 1. Relapse free survival of patients in stages I-III at the time of initial diagnosis $(\mathrm{N}=137)$.

Genetics and Molecular Research 16 (1): gmr16019369 
A total of 58 patients in the overall cohort died (19\%). The mortality rate was higher for patients with tumors bearing the mutated $K$-ras $(26 \%)$ than in patients with the wild-type $K$-ras $(15 \%)[\mathrm{OR}=1.72(95 \% \mathrm{CI}=1.08-2.74), \mathrm{P}=0.020]$. Similarly, for patients with stage IV tumors at the time of diagnosis, $34 \%$ of the patients with mutated $K$-ras tumors died, compared to $19 \%$ for those bearing the wild-type $K$-ras tumors [OR $=1.84(95 \% \mathrm{CI}=1.07$ $3.18), \mathrm{P}=0.024]$. Median OS in this group was 23.5 months for patients with the mutated $K$-ras tumors, while patients with the wild-type $K$-ras tumors did not reach the median survival $(\mathrm{P}=0.0357$; Figure 2). Serum CEA at presentation $(\mathrm{P}=0.0019)$ and $K$-ras status $(\mathrm{P}=0.023)$ significantly affected OS in the univariate analysis and both remained statistically significant in the multivariate analysis $(\mathrm{P}=0.004$ and $\mathrm{P}=0.44$ respectively; Table 3$)$.

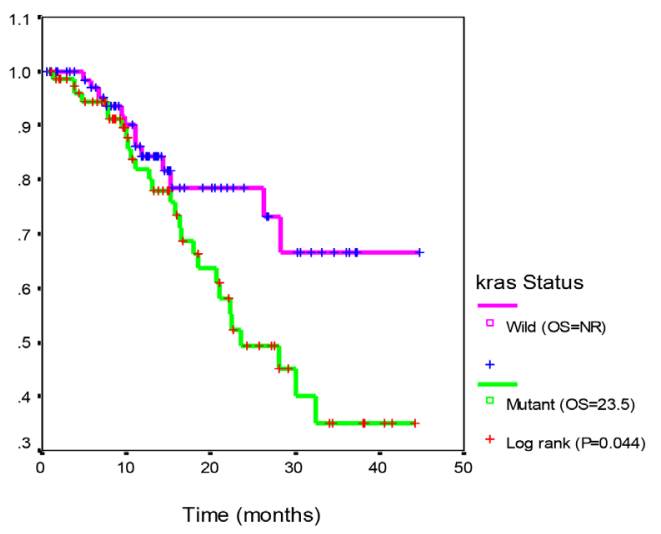

Figure 2. Overall survival of patients with stages IV at initial diagnosis $(\mathrm{N}=163)$.

\section{DISCUSSION}

Large phase III trials investigating the efficacy of the anti-EGFR antibodies in treating patients with mCRC represent the most reliable and comprehensive source of data on the relationship between treatment outcomes and the genetic status of $K$-ras. These trials recruited patients mostly from western countries, with a $K$-ras mutation rate of about $40-45 \%$ (Douillard et al., 2010; Ibrahim et al., 2010; Peeters et al., 2010). Evidence suggests that the molecular pathology of CRC in the Middle Eastern patients is different than that of patients from the western world (Soliman et al., 2001). A difference in the prevalence of $K$-ras mutations in mCRC has also been described according to the geographic area of residence, with a higher prevalence found in western Europe compared to areas outside Europe (Van Cutsem et al., 2011).

Variations in the study design complicate comparisons between studies in this area, particularly regarding the inclusion of patients at different stages of the disease, reporting of the disease stage, whether the reported stage was at the time of diagnosis or at the time of data collection, and the lack of mutation rate reports in metastatic or non-metastatic diseases. Previous studies from the Middle East (or in the Arab population) that enrolled a relatively large number of patients and included patients with different stages of the disease, reported K-ras mutation rates of 28-56\% in Saudi Arabia (Abubaker et al, 2009; Zahrani et al., 2014; Beg et al., 2015; Dallol et al., 2016), 33-45\% in Turkey (Gumus et al., 2013; Baskin et al., 2014), and 33-44\% in Jordan (Elbjeirami and Sughayer, 2012; Gumus et al., 2013). Lower

Genetics and Molecular Research 16 (1): gmr16019369 
mutation rates were observed in countries to the west of Saudi Arabia, such as Egypt (11-18\%) (Soliman et al., 2001; Gumus et al., 2013), and Morocco (24\%) (Marchoudi et al., 2013). To our knowledge, our study includes the second largest number of patients with metastatic disease, after 1,106 patients enrolled in one study in Turkey (Gumus et al., 2013). The prevalence of mutated $K$-ras in our study was $42 \%$ in patients who were mostly in stages II-IV of mCRC, and is broadly concordant with data from other Middle Eastern countries and the western world, within the limitations of comparison. The finding that about nine in ten mutations were in codon 12 was also similar to the findings from other countries in the region (Abubaker et al., 2009; Elbjeirami and Sughayer, 2012; Gumus et al., 2013; Marchoudi et al., 2013; Baskin et al., 2014) and elsewhere (Karapetis et al., 2008; Zalis et al., 2009; Gil Ferreira et al., 2014). We found that mutant $K$-ras tumors were more likely to be present in patients in an advanced stage of the disease compared to those with the wild-type $K$-ras tumors. Other studies that included patients in all the stages of the disease did not report any association between $K$-ras genetic status and stage, including the two largest studies from the Middle Eastern region (Abubaker et al, 2009; Baskin et al., 2014). We found no significant association between $K$-ras genetic staus and other clinicopathological factors such as gender, age, tumor site, grade of tumor, LVI, PNI, and presentation with perforation or bleeding. Studies investigating these associations have yielded conflicting results with respect to gender (Porebska et al., 2000; Roth et al., 2010; Inoue et al. 2012), and age does not appear to predict $K$-ras mutation status reliably (Liang et al., 2003). Our finding that elevated CEA was associated with the presence of mutated $K$-ras confirms those of earlier studies (Selcukbiricik et al., 2013; Li et al., 2015). Higher CEA levels are associated with higher numbers of circulating tumor cells and poorer outcome (Chew et al., 2012; Das et al., 2015). Results of serum CEA at presentation were available in 120/163 patients who presented with stage IV metastatic disease with CEA levels $>40 \mu \mathrm{g} / \mathrm{L}$ in $60 / 120$ $(50 \%)$ cases. CEA levels were available in $88 / 137$ patients who presented with stages I-III of the early disease with CEA levels $>40 \mu \mathrm{g} / \mathrm{L}$ in only $14 / 88$ (15.9\%) cases. This indicates that there is a relationship between high serum CEA levels and the advanced stage of the disease during the presentation. Additionally, our results show a relationship between presence of the $K$-ras mutation and advanced stage of the disease (Table 3 ).

The prognostic value of the genetic status of $K$-ras is controversial, with studies associating $K$-ras mutation with shorter disease-specific survival (Nakanishi et al., 2013; Phipps et al., 2013) or no marked effect on prognosis (Karapetis et al., 2008; Roth et al., 2010). Other data suggest that $K$-ras mutation is associated with poor prognosis in patients in the early stage of CRC, but not in the advanced disease (Inoue et al., 2012; Phipps et al., 2013). Our results showed that $K$-ras mutation was a factor for poor prognosis in all patients irrespective of the disease stage; however, in the multivariate analysis, it was a factor for poor prognosis only in the patients with advanced disease. The effect on prognosis may depend on the nature of the specific mutations (Andreyev et al., 2001), which was beyond the scope of our study.

The primary endpoint of this study was to determine the frequency of the $K$-ras mutation in Saudi patients with CRC. The details of systemic treatment had not been collected, and thus, outcome (PFS and OS) was generated by an additional secondary analysis. We assumed that the majority of the patients with $K$-ras wild-type tumors, who developed the metastatic disease, would have received the anti-EGFR therapy as it became widely available in Saudi Arabia in 2007, and the majority of the patients in our population were diagnosed with colon cancer in 2007 or later, whereas only a minority (23 patients) were diagnosed between 2001 and 2006. The median OS for patients with stage IV wild-type $K$-ras tumors in our cohort

Genetics and Molecular Research 16 (1): gmr16019369 
was not reached (Figure 2). This may be partly due to the administration of a combination of chemotherapy and anti-EGFR antibodies. The results of recent trials investigating the efficacy of the anti-EGFR therapy in patients with mCRC show encouraging OS. For example, median OS were 28.7 and 29.9 months in the cetuximab treatment regimens of the FIRE-3 and CALGB/SWOG 80405 trials, respectively (Heinemann et al., 2014; Alan et al., 2014). In addition, the majority of our patients (79\%) had left-sided tumors and this may partly explain the excellent OS. It is increasingly being reported that leftsided tumors have a better outcome compared to those arising on the right side of the colon. Results of a recent analysis of the CALGB/SWOG 80405 trial were presented at the annual meeting of the American Society of Clinical Oncology, 2016 (ASCO). These showed that the median OS in patients who received cetuximab for treatment of wild-type $K$-ras tumors was 37.5 months and 16.4 months for those with left and right-sided tumors, respectively (Alan et al., 2016).

Strengths of our study are the relatively large size of the studied population, inclusion of patients in early and advanced stages of the disease, extensive analysis of potential clinicopathological features by univariate and multivariate analyses, and geographical coverage of approximately the entire western side of Saudi Arabia. Limitations of our study include a relatively small sample size compared to studies in the western population, lack of correlation of treatment outcomes with codon site and individual mutations, lack of association of mutation status with data on outcomes of treatment (particularly the anti-EGFR therapy), and non-inclusion of data pertaining to the mutations at codon 3 and 4 , which have recently been found to influence the outcomes of the EGFR-targeted therapy (Douillard et al., 2013; Bokemeyer et al., 2014; Ciardiello et al., 2014).

\section{CONCLUSIONS}

The prevalence of mutations in codons 12 and 13 of $K$-ras exon 2 was comparable between the Middle Eastern population and previous reports from the region and large international studies. These mutations were associated with adverse features during presentation of the disease, including advanced stage and higher serum CEA. In addition, they were also associated with poor outcomes in patients presenting with both early and advanced stages of the disease. Larger, collaborative, and multi-center studies in a wider geographical area of the Middle East are required to investigate the role of the genetic status of the extended Ras family members ( $K$-ras and $N$-ras) in CRC, with inclusion of treatment data.

\section{Conflicts of interest}

Authors declare no conflict of interest.

\section{ACKNOWLEDGMENTS}

We thank Dr. Mike Gwilt of GT Communications for editing the manuscript for language and style and Merck Serono for funding the editing. We thank Sawsan Bassi for helping us with the electronic reference management program.

Genetics and Molecular Research 16 (1): gmr16019369 


\section{REFERENCES}

Abubaker J, Bavi P, Al-Haqawi W, Sultana M, et al. (2009). Prognostic significance of alterations in KRAS isoforms KRAS4A/4B and KRAS mutations in colorectal carcinoma. J. Pathol. 219: 435-445 http://dx.doi.org/10.1002/path.2625.

Alan P, Venook, DN, Lenz HF, Innocenti F, et al. (2014). CALGB/SWOG 80405: Phase III trial of irinotecan/5-FU/ leucovorin (FOLFIRI) or oxaliplatin/5-FU/leucovorin (mFOLFOX6) with bevacizumab (BV) or cetuximab (CET) for patients (pts) with KRAS wild-type (wt) untreated metastatic adenocarcinoma of the colon or rectum (MCRC). $J$. Clin. Oncol. 32: 5s (suppl; abstr LBA3).

Alan P, Venook DN, Innocenti F, Fruth B, et al. (2016). Impact of primary $\left(1^{\circ}\right)$ tumor location on overall survival (OS) and progression-free survival (PFS) in patients (pts) with metastatic colorectal cancer (mCRC): Analysis of CALGB/ SWOG 80405 (Alliance). J. Clin. Oncol. 34: 2016 (suppl; abstr 3504).

Andreyev HJ, Norman AR, Cunningham D, Oates J, et al. (2001). Kirsten ras mutations in patients with colorectal cancer: the 'RASCAL II' study. Br. J. Cancer 85: 692-696 http://dx.doi.org/10.1054/bjoc.2001.1964.

Baskin Y, Calibasi G, Amirfallah A, Dagdeviren YK, et al. (2014). KRAS and BRAF mutation frequencies in a series of Turkish colorectal cancer patients. Transl. Cancer Res. 3: 160-166.

Beg S, Siraj AK, Prabhakaran S, Bu R, et al. (2015). Molecular markers and pathway analysis of colorectal carcinoma in the Middle East. Cancer 121: 3799-3808 http://dx.doi.org/10.1002/cncr.29580.

Bokemeyer C, Kohne CH, Ciardiello F, Lenz HJ, et al. (2014).Treatment outcome according to tumor RAS mutation status in OPUS study patients with metastatic colorectal cancer (mCRC) randomized to FOLFOX4 with/without cetuximab. J. Clin. Oncol. 32: 5s (suppl; abstr 3505).

Chau I and Cunningham D (2009). Treatment in advanced colorectal cancer: what, when and how? Br. J. Cancer 100: 1704-1719 http://dx.doi.org/10.1038/sj.bjc.6605061.

Chew MH, Teo JY, Kabir T, Koh PK, et al. (2012). Stage IV colorectal cancers: an analysis of factors predicting outcome and survival in 728 cases. J. Gastrointest. Surg. 16: 603-612 http://dx.doi.org/10.1007/s11605-011-1725-1.

Ciardiello F, Lenz HJ, Kohne CH, Heinemann V, et al. (2014). Treatment outcome according to tumor RAS mutation status in CRYSTAL study patients with metastatic colorectal cancer (mCRC) randomized to FOLFIRI with/without cetuximab. J. Clin. Oncol. 32: 5s (suppl; abstr 3506)

Cunningham D, Humblet Y, Siena S, Khayat D, et al. (2004). Cetuximab monotherapy and cetuximab plus irinotecan in irinotecan-refractory metastatic colorectal cancer. N. Engl. J. Med. 351: 337-345 http://dx.doi.org/10.1056/ NEJMoa033025.

Dallol A, Buhmeida A, Al-Ahwal MS, Al-Maghrabi J, et al. (2016). Clinical significance of frequent somatic mutations detected by high-throughput targeted sequencing in archived colorectal cancer samples. J. Transl. Med. 14: 118 http://dx.doi.org/10.1186/s12967-016-0878-9.

Das A, Kunkel M, Joudeh J, Dicker DT, et al. (2015). Clinico-pathological correlation of serial measurement of circulating tumor cells in 24 metastatic colorectal cancer patients receiving chemotherapy reveals interpatient heterogeneity correlated with CEA levels but independent of KRAS and BRAF mutation. Cancer Biol. Ther. 16: 709-713 http:// dx.doi.org/10.1080/15384047.2015.1030555.

Douillard JY, Siena S, Cassidy J, Tabernero J, et al. (2010). Randomized, phase III trial of panitumumab with infusional fluorouracil, leucovorin, and oxaliplatin (FOLFOX4) versus FOLFOX4 alone as first-line treatment in patients with previously untreated metastatic colorectal cancer: the PRIME study. J. Clin. Oncol. 28: 4697-4705 http://dx.doi. org/10.1200/JCO.2009.27.4860.

Douillard JY, Oliner KS, Siena S, Tabernero J, et al. (2013). Panitumumab-FOLFOX4 treatment and RAS mutations in colorectal cancer. N. Engl. J. Med. 369: 1023-1034 http://dx.doi.org/10.1056/NEJMoa1305275.

Elbjeirami WM and Sughayer MA (2012). KRAS mutations and subtyping in colorectal cancer in Jordanian patients. Oncol. Lett. 4: 705-710 10.3892/ol.2012.785.

Gil Ferreira C, Aran V, Zalcberg-Renault I, Victorino AP, et al. (2014). KRAS mutations: variable incidences in a Brazilian cohort of 8,234 metastatic colorectal cancer patients. BMC Gastroenterol. 14: 73 http://dx.doi.org/10.1186/1471230X-14-73.

Gumus M, Dane F, Karabulut B, Uygun K, et al. (2013). Interim results of observational study to determine K-ras mutation rates in patients with metastatic colorectal cancer in Turkey (TURKRAS study). Eur. J. Cancer 49: S571-S571.

Heinemann V, von Weikersthal LF, Decker T, Kiani A, et al. (2014). FOLFIRI plus cetuximab versus FOLFIRI plus bevacizumab as first-line treatment for patients with metastatic colorectal cancer (FIRE-3): a randomised, open-label, phase 3 trial. Lancet Oncol. 15: 1065-1075 http://dx.doi.org/10.1016/S1470-2045(14)70330-4.

Ibrahim EM, Zekri JM and Bin Sadiq BM (2010). Cetuximab-based therapy for metastatic colorectal cancer: a meta-analysis of the effect of K-ras mutations. Int. J. Colorectal Dis. 25: 713-721 http://dx.doi.org/10.1007/s00384-010-0927-4.

Genetics and Molecular Research 16 (1): gmr16019369 
Inoue Y, Saigusa S, Iwata T, Okugawa Y, et al. (2012). The prognostic value of KRAS mutations in patients with colorectal cancer. Oncol. Rep. 28: 1579-1584 10.3892/or.2012.1974.

Karapetis CS, Khambata-Ford S, Jonker DJ, O'Callaghan CJ, et al. (2008). K-ras mutations and benefit from cetuximab in advanced colorectal cancer. N. Engl. J. Med. 359: 1757-1765 http://dx.doi.org/10.1056/NEJMoa0804385.

Kopetz S, Chang GJ, Overman MJ, Eng C, et al. (2009). Improved survival in metastatic colorectal cancer is associated with adoption of hepatic resection and improved chemotherapy. J. Clin. Oncol. 27: 3677-3683 http://dx.doi. org/10.1200/JCO.2008.20.5278.

Li W, Qiu T, Ling Y, Guo L, et al. (2015). Molecular pathological epidemiology of colorectal cancer in Chinese patients with KRAS and BRAF mutations. Oncotarget 6: 39607-39613 10.18632/oncotarget.5551.

Liang JT, Huang KC, Cheng AL, Jeng YM, et al. (2003). Clinicopathological and molecular biological features of colorectal cancer in patients less than 40 years of age. Br. J. Surg. 90: 205-214 http://dx.doi.org/10.1002/bjs.4015.

Marchoudi N, Amrani Hassani Joutei H, Jouali F, Fekkak J, et al. (2013). Distribution of KRAS and BRAF mutations in Moroccan patients with advanced colorectal cancer. Pathol. Biol. (Paris) 61: 273-276 http://dx.doi.org/10.1016/j. patbio.2013.05.004.

Nakanishi R, Harada J, Tuul M, Zhao Y, et al. (2013). Prognostic relevance of KRAS and BRAF mutations in Japanese patients with colorectal cancer. Int. J. Clin. Oncol. 18: 1042-1048 http://dx.doi.org/10.1007/s10147-012-0501-x.

Parkin DM, Bray F, Ferlay J and Pisani P (2005). Global cancer statistics, 2002. CA Cancer J. Clin. 55: 74-108. http:// dx.doi.org/10.3322/canjclin.55.2.74

Peeters M, Price TJ, Cervantes A, Sobrero AF, et al. (2010). Randomized phase III study of panitumumab with fluorouracil, leucovorin, and irinotecan (FOLFIRI) compared with FOLFIRI alone as second-line treatment in patients with metastatic colorectal cancer. J. Clin. Oncol. 28: 4706-4713 http://dx.doi.org/10.1200/JCO.2009.27.6055.

Phipps AI, Buchanan DD, Makar KW, Win AK, et al. (2013). KRAS-mutation status in relation to colorectal cancer survival: the joint impact of correlated tumour markers. Br. J. Cancer 108: 1757-1764 http://dx.doi.org/10.1038/ bjc. 2013.118 .

Porebska I, Harlozinska A and Bojarowski T. (2000). Expression of the tyrosine kinase activity growth factor receptors (EGFR, ERB B2, ERB B3) in colorectal adenocarcinomas and adenomas. Tumour Biol. 21: 105-115. doi:30116.

Roth AD, Tejpar S, Delorenzi M, Yan P, et al. (2010). Prognostic role of KRAS and BRAF in stage II and III resected colon cancer: results of the translational study on the PETACC-3, EORTC 40993, SAKK 60-00 trial. J. Clin. Oncol. 28: 466-474 http://dx.doi.org/10.1200/JCO.2009.23.3452.

Salomon DS, Brandt R, Ciardiello F and Normanno N (1995). Epidermal growth factor-related peptides and their receptors in human malignancies. Crit. Rev. Oncol. Hematol. 19: 183-232. http://dx.doi.org/10.1016/1040-8428(94)00144-I

Selcukbiricik F, Bilici A, Tural D, Erdamar S, et al. (2013). Are high initial CEA and CA 19-9 levels associated with the presence of K-ras mutation in patients with metastatic colorectal cancer? Tumour Biol. 34: 2233-2239 http://dx.doi. org/10.1007/s13277-013-0763-6.

Soliman AS, Bondy ML, El-Badawy SA, Mokhtar N, et al. (2001). Contrasting molecular pathology of colorectal carcinoma in Egyptian and Western patients. Br. J. Cancer 85: 1037-1046 http://dx.doi.org/10.1054/bjoc.2001.1838.

Van Cutsem E, Köhne CH, Hitre E, Zaluski J, et al. (2009). Cetuximab and chemotherapy as initial treatment for metastatic colorectal cancer. N. Engl. J. Med. 360: 1408-1417 http://dx.doi.org/10.1056/NEJMoa0805019.

Van Cutsem E, Köhne CH, Láng I, Folprecht G, et al. (2011). Cetuximab plus irinotecan, fluorouracil, and leucovorin as first-line treatment for metastatic colorectal cancer: updated analysis of overall survival according to tumor KRAS and BRAF mutation status. J. Clin. Oncol. 29: 2011-2019 http://dx.doi.org/10.1200/JCO.2010.33.5091.

Vogelstein B, Fearon ER, Hamilton SR, Kern SE, et al. (1988). Genetic alterations during colorectal-tumor development. N. Engl. J. Med. 319: 525-532 http://dx.doi.org/10.1056/NEJM198809013190901.

Zahrani A, Kandil M, Badar T, Abdelsalam M, et al. (2014). Clinico-pathological study of K-ras mutations in colorectal tumors in Saudi Arabia. Tumori 100: 75-79 10.1700/1430.15819.

Zalis MG, Vieira FM, Zalcberg-Renault I, Bonamino MH, et al. (2009). KRAS mutation profile in colorectal cancer patients in Brazil: A cohort of 989 individuals. J. Clin. Oncol. 27: e15017.

Genetics and Molecular Research 16 (1): gmr16019369 